\title{
La protección del medio ambiente como derecho y virtud. La ética kantiana de la responsabilidad con la naturaleza
}

\author{
Maximiliano HeRnándeZ Marcos
}

Universidad de Salamanca

RESUMEN. En este trabajo se presenta la ética de Kant como un programa práctico de responsabilidad con la naturaleza fundado en la exigencia normativa de realización mundana de los seres humanos como personas morales. Ese compromiso de responsabilidad ética con el medio ambiente funciona como límite de toda relación meramente instrumental con nuestro planeta al servicio de cualesquiera intereses empíricos de autoafirmación humana, y se despliega en una doble dirección: por un lado, como una relación de derecho del hombre a la utilización racional del entorno que ha de traducirse en una legislación pública global sobre el uso privado de las cosas; y, por otro lado, como una relación virtuosa del individuo consigo mismo en la que se acredita la propia índole moral a través del trato no destructivo de los seres inanimados y vivos de la naturaleza.

Palabras clave: Kant, medio ambiente, persona moral, responsabilidad ética.

En un pasaje polémico de sus Ensayos sobre asuntos diversos de moral, literatura y vida social (1792) en el que arremetía contra el primado de la moralidad sobre la felicidad en la Ética kantiana, Christian Garve, «filósofo popular» de raíz neoaristotélica, exigía tratar a los animales, en cuanto seres dotados de sentimientos, como fines en sí e incluir de esta manera el bienestar de los mismos en
ABSTRACT. In this work Kant's ethics are presented as a practical programme of responsibility towards nature founded on the normative demand for the worldly realization of human beings as moral persons. This commitment of ethical responsibility to the environment functions as a limit to any merely instrumental relation with our planet at the service of any empirical interests of human self-affirmation, and is deployed in two directions: on the one hand, as a relation of the right of mankind to the rational use of the environment which is to be translated into global public legislation on the private use of things, and, on the other hand, as a virtuous relationship of the individual with him or herself in which one's own moral nature is established through the non-destructive treatment of inanimate and living beings in nature.

Key words: Kant, the environment, moral person, ethical responsibility.

el «sistema de la felicidad» ${ }^{1}$. En su réplica al ilustrado silesio en Sobre el tópico: «tal vez eso sea correcto en teoría, pero no sirve para la práctica» (1793), Kant omitió cualquier comentario de esas palabras, no porque el bienestar de los seres vivos le fuera indiferente o la relación con ellos careciese para él de relevancia moral, sino probablemente porque, en consonancia con su valoración trascen- 
dental de la libertad de la persona humana, desechaba la idea de que las cualidades sensibles de los objetos o entidades naturales pudieran fundar relaciones genuinamente morales, con su correspondiente entramado de derechos y deberes. Ciertamente Kant no podía estar interesado en las cuestiones éticas relativas al medio ambiente como lo estamos hoy nosotros, puesto que en los inicios de la modernidad técnica e industrial la conservación de la naturaleza no constituía aún un problema histórico tan crucial como lo es en nuestros días. A pesar de ello, el pensador de Königsberg dedicó algunas páginas, sin duda breves, exclusivamente a este tema en las Lecciones de Ética y sobre todo en la segunda parte de la Metafisica de las costumbres (1797), concretamente los $\S \S 16-17$ de su Doctrina de la virtud, y su inclusión allí de los animales por primera vez en la órbita de la vida ética, de donde habían sido excluidos por la tradición iusnaturalista moderna, representa desde el punto de vista histórico un avance decisivo en el proceso de «secularización de la conciencia moral» ${ }^{2}$, toda vez que ello se produce al unísono con la reducción antropológica del papel moral de Dios, a quien se niega no ya sólo la condición de fuente de moralidad sino también la de sujeto de una relación ético-jurídica con el hombre.

Sin embargo, la recepción de la teoría moral kantiana en los debates contemporáneos en torno a la fundamentación de una Ética del medio ambiente se ha caracterizado más por el reproche condenatorio que por el reconocimiento no ya sólo de sus logros históricos, sino también de las posibilidades, en modo alguno desdeñables, que todavía hoy se vislumbran al respecto en un planteamiento moral que, precisamente por hacer de la persona humana su centro y fundamento, reclama sobre todo un compromiso de responsabilidad con nuestro ecosistema vivo, un compromiso del que depende no sólo - como es obvio, y así se ha destacado- la conservación biológica de la especie humana, sino sobre todo - he aquí la clave del argumento de Kant - la conservación moral de cada individuo, su realización ética como sujeto personal, su propia condición virtuosa. Algunos trabajos recientes (Höffe, Ingensiep, Baranzke...) han iniciado, no obstante, una valoración crítica y equitativa de los textos kantianos sobre el tema y han puesto de manifiesto - tal es la tesis central de Heike Baranzke - justamente esa implicación intrínseca del trato con la naturaleza en el compromiso moral de cada hombre consigo mismo ${ }^{3}$.

En esta misma dirección, el objetivo de este capítulo es mostrar que la Ética kantiana no conlleva un plan «antropocéntrico» de dominación y uso meramente instrumental de nuestro planeta vivo al servicio de cualesquiera intereses de autoafirmación empírica como especie natural (técnicos, económicos, políticos, eróticos, etc.), sino un proyecto «antropológico» de realización mundana de los seres humanos como personas morales, cuyo cumplimiento exige no sólo relaciones simétricas, ético-jurídicas, de igualdad entre los hombres mismos como sujetos libres, sino también relaciones asimétricas de responsabilidad con todos los seres naturales como objetos moralmente relevantes. Para ello, tras bosquejar el sentido general del proyecto moral kantiano, comenzaré estableciendo la distinción entre «personas» y «cosas» como supuesto doctrinal básico, a partir del cual se instaura un orden teleológico-valorativo en el mundo caracterizado por la relación entre «fines en sí» y «útiles» disponibles, sobre el que se funda un derecho del ser humano al uso y posesión de los objetos naturales, así como un deber correspondiente de cuidado, protección y utilización responsable de los mismos. De ahí que en la segunda y 
tercera parte se presente, por un lado, el significado ético del «derecho privado» como facultad para el uso racional del mundo y se exponga, por otro lado, el sentido virtuoso de la relación con los animales y con el resto de la naturaleza, tal como se desprende principalmente de los $\S \S 16-17$ de la Doctrina de la virtud.

\section{La idea de «humanidad» como} fundamento moral y la distinción «personas»/«cosas» como nuevo orden valorativo de la acción en el mundo

Si hubiera que resumir en tres ideas básicas el programa fundamental de la Ética crítica, habría que decir lo siguiente: Kant convierte al sujeto racional de la acción en el único bien moral de la existencia, entiende además este bien incondicionado en un sentido radicalmente «práctico», como la tarea humana irrenunciable de constituirse en sujeto libre en todas las esferas de la vida social y, en consonancia con ello, introduce un orden valorativo en el mundo, enteramente distinto del orden natural de los fenómenos, en virtud del cual las relaciones teleológico-prácticas del hombre con su entorno se articulan a partir de la distinción jerárquica entre «personas» y «cosas», entre sujetos (morales) de derechos y deberes y meros objetos de uso a disposición del arbitrio humano. Veamos estas tres ideas algo más en detalle.

1. La racionalidad como bien moral: el sujeto como único objeto universal del querer. Es sabido que de entre las diversas formulaciones del imperativo categórico [IC] en la Fundamentación de la metafísica de las costumbres (1785), la tercera vincula el principio formal de universalidad posible de una máxima o acción, establecido en la primera formulación, con la realización de la idea de humanidad ${ }^{4}$. Tal asociación constituye, sin duda, el paso decisivo en el giro antropo- lógico de la Ética kantiana hacia el sujeto moral como único fin y fundamento de una praxis objetivamente válida, ya que mediante ella se presenta la racionalidad misma como el único objeto de la facultad de apetecer que es intrínsecamente «bueno»y, por consiguiente, como el único «fin objetivo» (moral) de entre la infinita diversidad de bienes o fines subjetivos que los hombres pueden perseguir al actuar. A este giro copernicano de la Ética, que hace depender lo (moralmente) «bueno» de la voluntad racional, y no a la inversa, es a lo que Kant denomina «la paradoja del método en una crítica de la razón práctica» ${ }^{5}$.

Pero ¿qué significa hacer de la forma de la racionalidad el objeto del querer? Obviamente supone convertir la inteligencia pura, mediante el único signo que la identifica, a saber, mediante la ley de su libertad incondicionada, en la única meta o propósito de la acción humana. Mas actuar de este modo, persiguiendo en el mundo fenoménico la racionalidad pura, equivale a constituir una subjetividad no-empírica de la voluntad, a proponerse como objeto universalizable de la conducta la subjetividad universal del querer, a la cual Kant da el nombre de "personalidad moral» por analogía con la categoría relacional de «sustancia»(/sujeto), o también, en expresión menos precisa pero más difundida, «humanidad» [Menschheit $]^{6}$. Haciendo, pues, del sujeto moral el único eje de vertebración objetiva de la praxis humana Kant lleva a cabo y consuma su revolución en la Ética. De esta manera, el sujeto racional de los fines, la humanidad, como fin incondicionado de nuestras relaciones teleológico-prácticas, se convierte también en la condición limitativa o «negativa» de cualesquiera fines subjetivos $\mathrm{y}$ empíricos que nos propongamos:

«Pues si en el uso de los medios para todo fin debo yo limitar mi máxima a la condición de su validez universal como ley para 
todo sujeto, esto equivale a que el sujeto de los fines, esto es, el ser racional mismo, no debe nunca ponerse por fundamento de las acciones como simple medio, sino como suprema condición limitativa en el uso de todos los medios, esto es, siempre al mismo tiempo como fin» ${ }^{7}$.

2. La tarea práctica de constituirse como sujeto libre: dignidad humana, personalidad moral, «reino de los fines». El desplazamiento kantiano de la moralidad desde los actos hacia la subjetividad racional tiene como presupuesto la libertad del hombre en su sentido genuino, «trascendental», de «autonomía» o capacidad de autolegislación de la razón pura ${ }^{8}$, con absoluta independencia del orden natural de las cosas. De hecho, para Kant el mundo moral no es más que la expresión única y la valoración suprema de la libertad misma. En este aspecto, actuar considerando siempre la humanidad como fin irrenunciable del querer equivale a constituir(se) y ser un sujeto libre en el mundo. Para el filósofo de la emancipación ilustrada, está claro que éste es el mayor bien, el único inalienable, que el ser humano racional puede desear en la vida.

Esta radicación de la racionalidad y de su cualificación práctico-valorativa como bien moral en la libertad del hombre explica asimismo algunos aspectos esenciales del criticismo moral. En primer lugar, a la condición libre del ser humano le es inherente que tanto la razón o inteligencia pura como la idea misma de «humanidad» no constituyan entidades sustanciales cerradas y estáticas, sino que más bien definan un proyecto de vida cuya realidad (práctica) consiste en su permanente actualización. Dicho en otros términos: se es racional en la medida en que se decide (o uno se atreve a) serlo convirtiendo libremente en máxima de nuestra acción la ley de universalidad posible; la racionalidad es, por tanto, entera responsabilidad nuestra y exige una voluntad constante de ser racionales ${ }^{9}$. En el mismo sentido, la humanidad «propiamente no es, se hace queriéndola y obrando moralmente, optando continuamente por ella» ${ }^{10}$.

Pero justamente en esta opción o decisión firme y constante por la racionalidad estriba, en segundo lugar, nuestra dignidad humana como seres privilegiados de la naturaleza, de suerte que, en este aspecto, una conducta racional es preferible a una irracional, porque aquélla es la única que permite considerarnos como seres dignos y exigir a los demás que nos consideren como tales, esto es, representa la única forma de constituirnos como sujetos morales. Ello significa ante todo que la dignidad, la valoración o consideración de nosotros mismos como fines en sí, no está dada por nacimiento sino que se conquista a diario. De ahí que el hombre - afirma Kant — pueda rebajarse a una condición inferior a la del animal, y que quien se arrastre como gusano no pueda quejarse de que le pisen ${ }^{11}$. Pero significa también que la altura moral, el grado de dignidad de cada individuo, en cuanto dependiente de la voluntad de ser sujeto racional de la acción, no se adquiere sólo a través de actos puntuales y dispersos intencionalmente buenos, sino mediante la continuidad y firmeza en el obrar según la ley, mediante la coherencia interna en la conducta de buena voluntad. Kant ha caracterizado por ello la subjetividad o «personalidad moral» como la "capacidad [Vermögen] de un ser sometido a las propias leyes prácticas puras» ${ }^{12}$, es decir, como el poder efectivo para el obrar autónomo que se acredita por una cierta constancia en las buenas acciones. En último término se trata de constituir (se como) un sujeto racional del querer, de formar un análogo práctico de la «sustancia», algo que sólo podemos valorar (¡jamás conocer!) a través de la «permanencia» de sus efectos fenoménicos (determinados actos) en el sujeto em- 
pírico del querer, esa especie de consistencia o «carácter moral» que nos permite identificar a una persona virtuosa.

El significado valorativo de la dignidad humana permite comprender, por último, el postulado intersubjetivo de la moralidad kantiana, así como la reciprocidad de los sujetos morales que interactúan ${ }^{13}$. Pues la posibilidad de llegar a ser una subjetividad universal del querer depende no sólo de que yo me considere a mí mismo como tal al actuar, sino también y principalmente de que todos compartan el valor absoluto de la «humanidad» como fin en sí del obrar, actúen consecuentemente de conformidad con él y sean capaces, por tanto, de reconocer el sentido moral de determinados actos. Sin esta comunidad interpersonal de la acción y del reconocimiento de sujetos morales difícilmente pueden establecerse relaciones prácticas de dignidad entre los hombres, que escapen a la inercia teleológico-instrumental de la cosificación característica de la mera dominación y de la fuerza. De ahí que Kant haya formulado en la Fundamentación de la metafísica de las costumbres, a través de la idea de un «reino de los fines», la universalización de la idea de humanidad y, por ende, de la comunidad práctica de sujetos libres como una exigencia normativa incondicionada: la de contribuir a un orden común «realmente universal de personas morales, que se relacionen de hecho entre ellas como fines en sí y no simplemente como medios» ${ }^{14}$.

3. La distinción «personas»/«cosas»: Hacia una ética de la acción en el mundo.

La idea de un «reino de los fines» nos sitúa precisamente ante la cuestión decisiva de la fundamentación kantiana de las relaciones morales con el medio ambiente, ya que esa doctrina, lejos de contener un alegato a favor de la vida contemplativa y de la pasividad de las buenas conciencias cerradas sobre sí mis- mas, como si de una especie de comunidad de espíritus puros se tratara, encierra una propuesta de ética mundana, orientada a la ordenación racional de la acción del hombre sobre la Tierra, constituye, pues, un programa moral de intervención en el mundo y de compromiso con él como forma de realización práctica de la libertad. Y este programa empieza por el reconocimiento de la totalidad del ser humano, incluida su naturaleza sensible, como fin en sí, es decir, como persona, en la medida en que se haga de la realización de la humanidad el centro de gravitación de toda la vida práctica ${ }^{15}$. Mas con esta valoración absoluta de la integridad natural del ser humano en función de su personalidad inteligible se sientan al mismo tiempo las bases conceptuales para la definición del tipo de relación práctica con la naturaleza en su conjunto que se deriva de la tarea moral del hombre.

Esa relación práctica se halla, en efecto, marcada por el (nuevo) orden $v a$ lorativo que se introduce en el mundo fenoménico como consecuencia del reconocimiento de un comienzo absoluto en la cadena de eventos-acciones por parte del sujeto racional libre. El orden natural, carente de por sí de valor y de significado moral, lo adquiere desde el momento en que se inserta en un horizonte distinto, el de la acción humana, y es contemplado ahí concretamente desde el punto de vista de la realización de la «humanidad» en nuestra propia persona. Pues entonces queda sometido a una jerarquía de valores caracterizada por la diferencia radical entre aquello a lo que otorgamos un valor absoluto y sagrado por constituir precisamente el comienzo incondicionado de la serie valorativa, y lo que tiene para nosotros sólo un valor relativo y condicionado. Kant ha formulado este orden jerárquico-valorativo a través de la célebre distinción entre «personas» y «cosas», entre los seres que en virtud de su racio- 
nalidad y personalidad moral poseen el valor supremo de la «dignidad» y se elevan por encima del resto del mundo sensible, y aquellos otros seres que, carentes de razón, sólo tienen un valor en relación con nosotros, con nuestros sentimientos, apetitos, inclinaciones o con cualesquiera otros propósitos de nuestra acción.

Esta distinción, que establece la superioridad ético-práctica del hombre sobre la naturaleza entera, ha sido caracterizada (y fundamentada) por el propio Kant desde dos puntos de vista diferentes pero relacionados entre sí. Por un lado, desde la perspectiva de la red teleológica de la acción humana - la más conocida, desarrollada en la Fundamentación y en la Crítica del discernimiento-, la «persona» humana se define como fin en sí mismo y «fin final» de la naturaleza, es decir, como el único fin («objetivo») del querer sustraído a la mera instrumentalización propia de las relaciones teleológico-prácticas del hombre; frente a ella, los restantes seres naturales son «cosas», porque se valoran, dentro de esta red teleológico-práctica, como meros fines «subjetivos», contingentes y ocasionales de la acción, esto es, como objetos susceptibles de convertirse en simples medios «útiles» para cualesquiera otros fines del arbitrio humano ${ }^{16}$. Por otro lado, desde el punto de vista de la relación $s u$ jeto/objeto moral, a la que en último término remite la perspectiva anterior, la «persona» se caracteriza por ser siempre sujeto moral, incondicionado, y, por tanto, susceptible de imputación por sus actos en virtud de su libertad, mientras que las «cosas», al carecer de esta capacidad racional, sólo pueden ser objetos (pero nunca sujetos) de una relación moral. Este planteamiento aparece formulado en la «Introducción» de La metafísica de las costumbres con plena nitidez:

«Persona es el sujeto, cuyas acciones son susceptibles de imputación [Zurechnung]. [...]
Una cosa es algo que no es susceptible de imputación. Todo objeto del libre arbitrio, carente él mismo de libertad, se llama, por tanto, cosa (res corporalis)» ${ }^{17}$.

La importancia de esta última caracterización reside en que lleva implícita la idea de que sólo las personas humanas, en virtud de su imputabilidad libre, se erigen en sujetos de derechos y deberes, mientras que el resto de seres naturales, carentes de subjetividad pura práctica, no pueden poseerlos ${ }^{18}$, y merecen a lo sumo una consideración moral como objetos implicados en la realización de la «humanidad» en nuestra persona. Puesto que la relación práctica con la naturaleza (y no sólo con los demás hombres) forma parte del proyecto moral de constituirse como sujetos libres, el trato con ella puede serle imputado al hombre, no porque haya un deber moral para con el mundo (lo hay únicamente para con sujetos personales), sino porque existe una responsabilidad (en la relación) con él. El modo como ha de configurarse esa relación práctica responsable con la naturaleza ha sido desarrollado por Kant en un doble sentido: por un lado, como una relación de derecho del hombre al uso racional de las cosas del mundo, y, por otro lado, como una relación de virtud (deber) del hombre consigo mismo a través del trato no-destructivo de los seres inanimados y vivos de la naturaleza. De este doble tipo de relación práctica de las «personas» humanas con las «cosas» naturales nos ocupamos en los apartados siguientes.

\section{El derecho de la «humanidad» al «uso» de la naturaleza: dominio y protección jurídica del mundo}

El rendimiento filosófico que cabe extraer de la Doctrina del Derecho para una comprensión plena y cabal de la aportación kantiana a una Etica del medio ambiente no ha sido suficientemente destacado por 
la historiografía sobre el tema, en la cual es frecuente que la perspectiva jurídica sea desatendida a favor de la estrictamente «ética» o virtuosa en la mayoría de las reconstrucciones históricas al respecto. Sin una consideración exhaustiva de este punto difícilmente se entendería, empero, no ya sólo el proyecto moral de Kant, sino también la importancia que para el mismo tiene el uso de la naturaleza por parte del hombre y la necesidad, derivada de ahí, de una regulación legal del mismo a nivel mundial, de una «globalización» — valga la expresión- de las leyes de protección de nuestro planeta vivo. Es preciso por ello exponer primero lo que significa el derecho del ser humano a la posesión de las cosas y el modo como Kant lo fundamenta racionalmente al comienzo de su teoría del «Derecho privado». Guiados por esta concepción general, podremos luego averiguar en qué sentido el derecho al uso de la naturaleza contribuye al programa moral de constituirse en sujetos libres y en qué medida el cumplimiento de este programa conlleva un compromiso de responsabilidad jurídica con respecto a la utilización de los bienes naturales, que ha de cristalizar en una legislación planetaria de conservación y uso racional del mundo en que vivimos. Semejante regulación global de nuestra relación con el medio ambiente se presenta como un asunto de «justicia participativa común» en la riqueza natural de la Tierra, una exigencia jurídico-normativa que se sigue inmediatamente de la idea de «humanidad» en la persona de todos los seres humanos, actuales y futuros.

a) Concepto y posibilidad de un «derecho a las cosas»: el «postulado jurídico de la razón práctica» y la idea de la "posesión común originaria» de la superficie terrestre

El lugar que mejor ilustra cómo Kant aspira a formular una Ética mundana, orienta- da a la actividad en la naturaleza y en la sociedad, es probablemente el capítulo primero de la doctrina sobre el «Derecho privado». Allí se plantea el problema de la relación entre las personas y las cosas en los términos jurídico-trascendentales siguientes: ¿cómo es posible que yo (sujeto-persona) pueda declarar «Mío» un objeto exterior a mí? La cuestión se refiere, sin duda, a la fundamentación de los derechos adquiridos en general y, particularmente, al derecho de propiedad sobre las cosas ${ }^{19}$.

La respuesta iusnaturalista clásica (la de Locke, por ejemplo), o al menos la más extendida en los tiempos de Kant, consistía en afirmar que el único fundamento para declarar algo jurídicamente mío es la posesión física del objeto. Esta postura, que cabría denominar «realismo de la posesión», es criticada por Kant debido a que restringe la posibilidad de un derecho sobre objetos al hecho de la mera «tenencia» o posesión empírica de los mismos. De acuerdo con tal posición no podríamos ampliar nuestros derechos sobre las cosas más allá de donde alcanzase la esfera de acción de nuestro propio cuerpo, es decir, de lo que Kant llama Mio interior o derecho innato: el derecho a la mera libertad externa del arbitrio (libertad de acción y decisión) que corresponde a todo individuo en virtud de su condición suprasensible de persona moral antes de cualquier acto jurídico ${ }^{20}$. Mas si redujésemos la posibilidad de adquirir las cosas a una mera extensión de esta «libertad innata» estaríamos limitando la apropiación legítima de objetos al «uso» necesario para la satisfacción de nuestras necesidades naturales inmediatas o fines elementales de autoconservación biológica, de suerte que quedarían entonces multitud de objetos o cosas sin ser utilizadas por nosotros y serían, por tanto, cosas sin dueño, res nullius, lo cual es inadmisible para Kant, porque supone 
negar la posibilidad de que todas las cosas de la Tierra sean útiles para el hombre.

La clave del argumento kantiano contra la fundamentación iusnaturalista clásica del derecho al uso de la naturaleza reside, por tanto, en poner de manifiesto que la mera libertad innata de las personas es perfectamente compatible con la existencia y posibilidad misma de cosas sin dueño, en la medida en que la privación en el uso de los objetos del mundo no implica intervención coactiva alguna en la integridad (física y moral) de las personas, como sería el caso, en cambio, si alguien me impidiese hablar, me golpease físicamente, me forzara a abandonar el sitio que ocupo o me sustrajera una manzana de la mano ${ }^{21}$. El derecho innato a la libertad originaria, por lo mismo que puede preservarse mediante la concordancia universal de los arbitrios humanos inactivos, no está en condiciones de garantizar una relación jurídico-práctica con las cosas de la naturaleza más allá de la mera posesión física de ellas, de manera que no es posible derivar de él las dos condiciones racionales en las que, según Kant, ha de fundamentarse el derecho de propiedad: la universalidad en la extensión del derecho de los hombres al uso de las cosas del mundo y el correspondiente valor de utilidad o utilizabilidad de la naturaleza en su conjunto para la persona humana.

Ahora bien, ¿desde dónde cabe fundamentar una relación jurídico-práctica con el mundo externo que cumpla estas dos condiciones a priori? Si no puede hacerse a partir de la libertad (empírica y meramente) negativa del arbitrio, ¿qué libertad es capaz de sancionar un derecho universal a la posesión de todas las cosas de tal modo que la sola posibilidad de no hacer uso (ni apropiarse) de algunas de ellas suponga un sacrificio o lesión de la misma? En los Trabajos preparatorios de la Metafísica de las costumbres Kant ofrece una respuesta suficientemente clara: el derecho de propiedad sólo puede fundamentarse en el concepto positivo (moral) de la libertad como "capacidad de autolegislación de la razón pura práctica» ${ }^{22}$. Pues sólo ésta, al no depender de ningún hecho o ley de la naturaleza, tampoco puede ser restringida por condiciones empíricas o naturales; en cuanto pura capacidad racional, tiene que acreditarse de manera efectiva mediante una relación práctica también puramente «intelectual» del hombre con el resto de los seres del mundo, una relación que, sin basarse en la posesión física constante de los mismos, conlleve, sin embargo, una «aprehensión en cierto modo permanente», a saber, esa aprehensión racional que consiste en tenerlos siempre a nuestra disposición en virtud de una mera voluntad pura de uso ${ }^{23}$. A esta relación racional pura, la propiamente jurídica, del ser humano con los objetos externos la denomina Kant "posesión inteligible (possessio noumenon)» y a la doctrina que fundamenta en ella el derecho de propiedad «idealismo de la posesión». De acuerdo con ella se reconoce en virtud de un acto de autodeterminación libre del arbitrio por la humanidad en nuestra persona la disponibilidad ilimitada de uso del mundo natural para el hombre como un derecho del sujeto moral a la posesión de las cosas. Esto es precisamente lo que establece, como supuesto fundamental del Derecho Privado, el así llamado «postulado jurídico de la razón práctica»:

«§2. Es posible tener como mío cualquier objeto exterior de mi arbitrio; es decir, es contraria al derecho una máxima según la cual, si se convirtiera en ley, un objeto exterior del arbitrio tendría que ser en sí (objetivamente) un objeto sin dueño (res nullius)» ${ }^{24}$.

Sin duda, este postulado de apropiación posible de cualquier objeto material por parte del hombre sanciona jurídica- 
mente el dominio sobre la naturaleza en los términos bíblicos de una relación instrumental con el mundo al servicio de cualesquiera fines, tal como ya reconociera Kant en Presunto comienzo de la historia humana $(1786)^{25}$. Para hacer posible este uso discrecional de los objetos externos conforme a razón y fundar así una relación jurídica efectiva también con las cosas materiales el postulado de la adquisición amplía el concepto formal de derecho más allá de la «libertad innata» y de su esfera limitada de acción corporal. De esta manera garantiza la posibilidad de realización de la humanidad como fin en sí en la persona física de todo hombre estableciendo que el uso de la naturaleza es materia de libertad (moral) y, por tanto, racionalmente regulable, y que por eso la relación jurídica con ella debe asegurar la constante disponibilidad de las cosas para ser utilizadas sin limitación empírica alguna, con independencia de si están eventualmente en algún tipo de relación fenoménica con nuestro cuerpo.

Ahora bien, semejante ampliación del derecho a la posesión de objetos naturales para garantizar la dignidad de la persona humana en las relaciones teleológico-prácticas, instrumentales, de intercambio social no lleva consigo a su vez el reconocimiento de las cosas como sujetos de obligación (y eventualmente obligantes), sino más bien un compromiso con el resto de los seres humanos derivado de la imposición de una restricción a la libertad de acción innata de los mismos como consecuencia del carácter privado que tiene cualquier adquisición jurídica del mundo material, y de la subsiguiente prohibición que implica para los demás hombres de usar determinados «objetos de nuestro arbitrio, porque los hemos tomado de antemano en nuestra posesión» ${ }^{26}$. La autorización (racional) de esta injerencia, en sí ilegítima, en el derecho innato de las personas a su integridad, convierte cierta- mente al postulado jurídico en una «ley permisiva de la razón práctica, que nos confiere la facultad jurídica [Befugnis]» ${ }^{27}$ para obligar a otros con respecto al uso de las cosas, pero al mismo tiempo lleva aparejada una exigencia de reciprocidad y universalidad en el reconocimiento de esta competencia jurídica que sólo puede cumplirse bajo la condición de un consentimiento común de todos los arbitrios libres en adquirir igual y paritariamente derechos de uso sobre los objetos materiales. De ahí que Kant, junto al «postulado jurídico de la razón práctica», haya formulado el supuesto complementario de una «posesión común originaria» del suelo terrestre y de la correspondiente voluntad universal unida de todos los posibles poseedores como única validación jurídica de cualquier adquisición particular de una cosa ${ }^{28}$.

Esta idea del fundamento comunitario e incluso cosmopolita del derecho de propiedad contiene al menos tres aspectos relevantes para nuestro tema. En primer lugar, significa que no cabe hablar de una relación jurídica (inmediata y recíproca) entre personas $y$ cosas sino de una relación mutua universal entre personas morales con respecto al uso individualizado de las cosas. Kant lo dice taxativamente:

«Propia y literalmente entendido, no hay un derecho (directo) a una cosa, sino que se denomina así a lo que corresponde a alguien frente a una persona que está en posesión común con todos los demás» ${ }^{29}$.

El derecho, como concepto puro de la razón práctica, se puede predicar sólo de relaciones interpersonales; jamás cabe atribuir a seres de la naturaleza, sin incurrir en una engañosa «personificación» ${ }^{30}$, derechos y obligaciones como si se tratara de sujetos morales; la naturaleza, mero fenómeno sensible, sólo puede ser objeto de uso en la relación jurídica que el hombre entabla con ella. 
En segundo lugar, el carácter originariamente comunitario del derecho al uso privado de las cosas indica que toda adquisición particular ha de pensarse «como un acto de distribución, de transferencia contractual por parte de la voluntad conjunta» ${ }^{31}$ de los posibles poseedores. Pues el concepto práctico a priori de una «comunidad originaria de posesión» del suelo terrestre no es más que la idea de que, si alguien está autorizado a apropiarse individualmente de una parte de la naturaleza — según el «postulado jurídico de la razón práctica»-, es porque todos los hombres, en virtud de su igualdad innata como personas morales, tienen una facultad jurídica [Befugnis] igual, un derecho subjetivo a adquirir una cierta porción de la superficie terrestre para su disfrute privado. Kant está, por tanto, vinculando el dominio jurídico del hombre sobre la naturaleza a la idea de una «justicia participativa» ${ }^{32}$ de todas las personas en el uso de nuestro planeta y sometiendo de este modo el derecho de propiedad privada a las únicas condiciones racionales, las de universalidad y reciprocidad, con las que dicha noción de justicia lo legitima.

Pero estas condiciones racionales sólo pueden verificarse, en tercer lugar, mediante una declaración expresa de consentimiento recíproco de todos capaz de garantizar la obligación mutua universal contraída con respecto al uso de las cosas por parte de cada uno. Ello significa que la comunidad originaria de posesión, como mera idea a priori de un derecho de todo hombre a la adquisición de bienes mundanos, tiene que transformarse en una voluntad realmente común de reconocimiento mutuo, universal y necesario de lo suyo de cada cual, es decir, ha de materializarse en una legislación genuinamente racional de todos los hombres (y por ello, en última instancia, cosmopolita) sobre el uso privado de las cosas naturales. Kant ha formulado esta idea como la necesidad de salir del estado de naturaleza social, donde todas las posesiones son jurídicamente «provisionales», para entrar en un «estado civil», bajo leyes públicas coactivas, donde las adquisiciones privadas reciben su validez jurídica «perentoria» ${ }^{33}$.

\section{b) La tarea de ser "señor de sí mismo» en la vida social: el derecho a la autonomía económica de la persona y la responsabilidad jurídica con la naturaleza}

Hay dos preguntas que es inevitable hacerse ante la fundamentación kantiana del derecho de propiedad. En primer lugar, parece justificado interrogar por qué el hombre necesita ampliar sus derechos más allá del trato social con los demás seres humanos y entrar, en este sentido, en relaciones con (respecto a) seres carentes de capacidad jurídica de cara al uso de los mismos, si con ello se expone a violar el derecho innato de las personas infringiendo la prohibición, contenida en el neminem laede, de restringir su libertad originaria. Y, en segundo lugar, dado que el «postulado jurídico de la razón práctica» autoriza un dominio pleno, ejercitado en privado, del hombre sobre la naturaleza, cabe plantearse si hay límites (jurídico-) racionales al uso de las cosas por parte de los seres humanos que impidan su instrumentalización absoluta. La respuesta a la primera cuestión ha de mostrarnos en qué sentido el proyecto moral de constituirse como sujetos libres requiere intervenir en el mundo apropiándose y sirviéndose de las cosas materiales. La segunda pregunta nos traslada al problema de los posibles «deberes jurídicos» del hombre con respecto a la naturaleza y al compromiso legal de responsabilidad en la conservación del medio ambiente.

1. La razón última por la cual Kant amplía el derecho más allá de la esfera 
originaria de la integridad de la persona para hacer posible la adquisición de bienes naturales parece bastante clara: se trata de asegurar la condición moral de ser «señor de sí mismo» (sui iuris) en la esfera privada de las relaciones sociales fundamentando la posibilidad de un dominium socioeconómico que capacite de manera real a los individuos para decidir según fines propios, sin depender del arbitrio coactivo de otras personas. El argumento de fondo es que los seres humanos podrán contar con una praxis digna en la vida diaria si además de (e incluso al margen de) ser reconocidos como sujetos iguales en el intercambio social de sus arbitrios libres y de sus estados («derecho contractual» y «derecho de sociedad doméstica»), se les garantiza sobre todo la condición básica y previa para afrontar ese intercambio social en términos de igual libertad de acción y decisión, sin exponerse a la mera instrumentalización de sus personas en la relación teleológico-práctica con los demás hombres. Esa condición garante de la libertad de sus arbitrios y, por ende, de la dignidad de sus personas en un territorio como el de la praxis social privada, dominado precisamente por relaciones de interés entre particulares, no puede ser otra, según Kant, que el derecho de propiedad (privada) o el derecho a una actividad laboral propia ${ }^{34}$, es decir, una relación jurídico-práctica de cierta permanencia (fenoménica) con las «cosas» materiales que asegure la independencia económica de los individuos gracias a que se les autoriza a mantener precisamente una constante relación instrumental de uso con la naturaleza. El motivo que justifica, pues, el «postulado jurídico de la razón práctica» viene a ser éste: que los hombres necesitan entablar relaciones de posesión con las cosas naturales no tanto para asegurarse la supervivencia física como seres sensibles, cuanto más bien para alcanzar su autonomía social como personas morales, para constituirse como sujetos libres en las relaciones externas de interés con los restantes seres humanos. Dicho de otro modo: la realización del hombre como fin en sí conlleva el reconocimiento de un derecho a la conservación de la autonomía de su persona en la praxis social, una autonomía privada que - así lo entiende Kant - sólo puede acreditarse mediante algún tipo de apropiación de la naturaleza, ya que al ser ésta la única forma de relación teleológico-práctica con una «sustancia» (corpórea), constituye también el único «sustrato» sólido para la libertad del arbitrio.

La importancia central de esta autonomía práctico-privada la ha reconocido Kant no sólo al erigirla en criterio de «personalidad civil», es decir, de ciudadanía política ${ }^{35}$, sino también al vislumbrar en ella la condición material de (mantenimiento de) la personalidad moral misma, esa clase de adquisición práctica sin la cual difícilmente podrá salvaguardarse el derecho originario a la integridad de la persona. Así, en los Trabajos preparatorios de la Metafísica de las costumbres se arguye al respecto contra el «realismo de la posesión» que la libertad de acción, en el sentido negativo de la independencia que corresponde a todo hombre en virtud de su «humanidad» (lo «Mío interno»), se autodestruiría si no pudiera acreditarse jurídicamente como «libertad de uso» más allá de la contingencia de las condiciones empíricas de relación del cuerpo con las cosas (lo «Mío exterior»), si no llegara, pues, a configurarse como una capacidad para «actuar según fines propios y en ningún caso según el fin de otros, [...], es decir, para no servir meramente como medio para cualquier fin ajeno (o para no ser coaccionado a ello)» ${ }^{36}$.

2. La cuestión de la responsabilidad jurídica del hombre con respecto a la na- 
turaleza ha de decidirse, desde la perspectiva moral de Kant, a partir del sentido republicano del dominium sobre las cosas, de la idea normativa complementaria de justicia participativa que formula el concepto racional de «posesión común originaria» de la superficie terrestre, y de la doctrina teórica del «realismo empírico», que supone admitir la heterogeneidad irreductible del mundo natural como un orden «sustancial» propio, ontológicamente distinto del sujeto racional, por más que desde el punto de vista práctico tenga sólo el valor relativo de un simple medio de utilidad en la cadena teleológica de la acción humana. Sólo desde estos supuestos cabe plantear en serio la idea de los límites jurídicos a la intervención humana en el medio ambiente, a saber: que el derecho al uso de la naturaleza ha de ir acompañado del correspondiente deber de responder también jurídicamente de ese uso, no sólo por las acciones de libertad y de restricción del arbitrio de los demás hombres que ello conlleva, sino también por la asunción, inherente a aquella facultad de uso, del carácter «sustantivo» del mundo natural como entidad empírica no reductible a nuestra representación subjetiva del mismo ni a una mera prolongación imaginaria de nuestra acción temporal sobre él, y que ha de mantenerse en la condición de «útil» para el hombre en general a lo largo de la historia. Veámoslo más en detalle.

Hemos señalado más arriba que el «postulado jurídico de la razón práctica» formula un imperativo de dominio sobre la naturaleza que sanciona el valor instrumental de la misma como objeto de un derecho a su uso por parte del hombre. No se trata, sin embargo, de un derecho de apropiación absoluta y arbitraria de nuestro planeta en función de cualesquiera intereses particulares (tecnológicos, económicos, hedonistas, lúdicos, etc.) para el que no quepa reconocer límite jurídico alguno, tal como se desprende de la concepción «liberal-moderna» - derivada de la(s) revolución(es) científica(s) e industrial(es) - de la «dominación» técnico-económica potencialmente ilimitada del mundo hasta el extremo de la aniquilación o agotamiento de sus recursos naturales. Al contrario, Kant contempla ahí sólo el derecho a la realización de la persona humana como fin en sí en la esfera social de su vida privada a través de la autosuficiencia económica, en consonancia con la idea del dominium o autonomía doméstica inherente a la libertad «republicana», que él reformula, no obstante, en los términos liberal-burgueses de propiedad privada y de autosuficiencia del sujeto productor libre ${ }^{37}$.

Ahora bien, esta idea del dominio socioeconómico contiene, en lo concerniente al trato con la naturaleza, solamente el postulado de la utilidad de la misma para el hombre como fundamento y límite a la vez de la relación jurídica con las cosas. Por un lado, el ser humano, de cara a realizarse como fin en sí a través de la independencia práctica de su persona, tiene un derecho a explotar y servirse de todos los seres y medios naturales para su propio sustento y bienestar. De ello forma parte, por ejemplo, el «derecho a matar» a los animales, o a que «trabajen» al servicio del hombre, o incluso a que se sometan a «experimentos» científicos ${ }^{38}$, con el fin de asegurar y mejorar las condiciones materiales de nuestra existencia. Mas, por otro lado, la legitimidad o la validez jurídica de esa relación instrumental con nuestro entorno cesa allí donde termina la utilidad de la misma para los fines de la autoconservación física e independencia socioeconómica de la voluntad individual, o donde se pone en peligro la conservación de la «sustancia» misma de la naturaleza como realidad distinta del sujeto racional, sobre la cual se funda precisamente su disponibilidad constante para ser utilizada siempre y universalmente por 
cualquier hombre. Este requisito de mantener el valor de utilidad en general, actual o futura, de la naturaleza como límite jurídico de la relación de dominio sobre ella sale claramente a relucir cuando Kant rechaza la destrucción arbitraria de partes del mundo inorgánico, porque con ello se priva a «otras personas» de «hacer uso» del mismo ${ }^{39}$, o cuando condena «los experimentos físicos acompañados de tortura» o crueldad realizados de manera superflua, por pura curiosidad teórico-lúdica («especulación» o mero «juego») ${ }^{40}$, o incluso cuando exige que el esfuerzo de los animales al servicio doméstico no vaya «más allá de sus propias fuerzas» ${ }^{41}$.

Ahora bien, esta convicción kantiana de que el ejercicio del derecho de propiedad privada se ha de ajustar a la exigencia de que las cosas poseídas permanezcan siempre en la condición práctica de útiles en general, por más que se hallen jurídicamente en nuestro poder, tiene su fundamento último en el requisito de reciprocidad universal de los arbitrios poseedores $\mathrm{y}$, por consiguiente, en la idea de que el dominio privado de la naturaleza se halla sujeto a las condiciones racionales de una justicia participativa común de todas las personas morales en el uso de nuestro planeta vivo. El concepto práctico a priori de una «posesión común originaria» de la Tierra como fundamento último de legitimidad de cualquier apropiación unilateral de la riqueza natural, en la medida en que postula la necesidad de un consentimiento universal de todos los hombres, apunta de este modo a la resolución del problema que no puede decidirse desde el mero derecho privado ni desde la sola parcialidad subjetiva de los arbitrios poseedores: el de determinar hasta dónde llega la utilidad y dónde empieza el abuso tanto en la relación individual de cada hombre con las cosas como en las relaciones prácticas entre los hombres con respecto al uso de las mismas.
En efecto, dado que el derecho de propiedad otorga al propietario un poder discrecional pleno de disposición sobre las cosas («ius disponendi de re sua») ${ }^{42}, \mathrm{y}$ el arbitrio libre de cada hombre es, en principio, ilimitado en su afán de posesión sobre el mundo externo, difícilmente podrán fijarse de manera objetiva, a partir de meros conceptos jurídico-privados, los $l i$ mites precisos de la utilidad y, por ende, los de la cantidad de bienes apropiables por parte de cualquier individuo. Esta indeterminación jurídico-privada con respecto a las cuotas justas de participación en la riqueza planetaria, y a la calidad en el uso de la misma ${ }^{43}$, está en el origen de los dos fenómenos históricos bien conocidos de «abuso» de la naturaleza: las enormes desigualdades socioeconómicas que dividen por doquier a los países y a los hombres, y el reciente deterioro ecológico del planeta Tierra, expuesto de continuo a la sobreexplotación unilateral de sus recursos con fines lucrativos y a la contaminación desconsiderada y subsiguiente malogro de sus bienes comunes (atmósfera, aguas de mares, fuentes y ríos, especies vegetales y animales...) como consecuencia de una aceleración tecnológica e industrial al servicio de un entramado de intereses económicos difícilmente universalizables y en modo alguno relacionados con la autonomía social de todas las personas humanas.

Frente a estos desmanes de corte jurídico-privado, Kant vino a sostener que la única manera de poner freno al «maltrato» del ecosistema vivo y a la privación de la subsistencia física de una amplia mayoría de seres humanos pasa, no por eliminar el derecho al uso privado de las cosas, sino por universalizarlo dotándole de fuerza legal efectiva. Ello significa que las cuotas justas de participación de todos los hombres en los bienes de la Tierra y los límites jurídicos de la utilidad de la naturaleza para el ser humano derivados del derecho 
de humanidad de toda persona moral a realizarse como fin en sí sólo pueden determinarse mediante una legislación pública global, que se «extienda a todo el género humano» ${ }^{44}$, sin la cual las relaciones de propiedad y uso del medio ambiente no pueden contar más que con una validez jurídica «provisional», con una mera presunción de derecho, carente de plena legitimación racional. Esta legislación de alcance global o cosmopolita conforme a la idea de justicia participativa común ha de incluir ciertamente leyes de garantías sociales y económicas suficientes como para salvaguardar el derecho a la actividad productiva o al menos a la supervivencia física de todos los hombres (leyes de educación generalizada, de ordenación justa del suelo y de la vivienda, de asistencia social en casos de necesidad...); pero también ha de asegurar, incluso como condición de posibilidad para el despliegue del ser humano como sujeto productor libre, la permanencia de la «sustancia» natural de uso y disfrute productivo mediante una normativa medio ambiental que proteja la naturaleza frente a los abusos arbitrarios y sancione la conservación de sus recursos y bienes materiales. He aquí la única forma de salvaguardar el derecho de la humanidad al uso de las cosas que asiste a priori, según la idea de la razón práctica, a las generaciones venideras como teóricas participantes en la «posesión común originaria» del suelo terrestre.

El fundamento de semejante legislación global protectora del medio ambiente no reside, según lo expuesto, en que la naturaleza sea o pueda ser sujeto de derechos, sino en que constituye más bien un objeto de responsabilidad jurídica para el hombre y, en cuanto tal, ha de canalizarse de manera universal, mediante una regulación positiva común de alcance cosmopolita. En este sentido, cabría decir, por tanto, que hay deberes jurídicos indirectos para con el medio ambiente, en la medida en que no corresponden a un derecho de la naturaleza como tal sino más bien al derecho de la humanidad en nuestra propia persona con respecto al uso de la naturaleza misma. Y esos deberes, al ser jurídicos, deben hallarse amparados por la fuerza coactiva de una ley con efecto sobre todos los habitantes de la Tierra.

\section{El deber "ético» de proteger la naturaleza: "virtud medioambiental» como dignidad moral de la persona}

El tratamiento breve de la relación del hombre con los restantes seres de la naturaleza desde una perspectiva estrictamente «ética» (no jurídica) llevado a cabo por Kant al final del libro primero de la Primera Parte de la Doctrina de la virtud, $\S \S 16-17$, así como en las Lecciones de Etica, pp. $287-290^{45}$, ha marcado ciertamente la recepción del criticismo práctico en los debates contemporáneos sobre la Ética del medio ambiente. El juicio predominante al respecto ha sido, empero, poco benevolente con los textos kantianos, en buena medida porque ha estado condicionado no sólo por la mirada metodológica de la Ética aplicada actual, sino también por una visión «naturalista» o al menos «naturalizante» del mundo, en la que se aspira, en líneas generales, a sustituir el criterio racional puro de «persona» por el criterio empírico-material de «capacidad de sentir» o de «sufrir» a la hora de fundamentar las relaciones morales de los seres humanos con los demás seres naturales. De ahí que la tópica de reproches lanzados en las últimas décadas contra la filosofía moral de Kant por su presunta incapacidad para una consideración ética de los animales (antropocentrismo e intelectualismo morales, prejuicios judeocristianos, concepción puramente instrumental de la naturaleza, etc.) se asemeje bastante, en sus argumentos, a la 
crítica radical a la que A. Schopenhauer, en su célebre escrito El fundamento de la moral (1840), sometiera a la razón pura práctica y a sus aplicaciones al trato de los animales en nombre de una ética de la «compasión» universal ${ }^{46}$.

Aunque hay razones suficientes en los textos kantianos para explicar esta recepción parcial, tan orientada por las urgencias del presente (oscuridad, brevedad y condensación de los escasos párrafos sobre el tema, algunas diferencias doctrinales entre las Lecciones de Ética y la Doctrina de la virtud, mezcla de argumentos genuinamente críticos sobre conducta medio ambiental con otros ampliamente difundidos en el siglo XVIII...), ello no justifica ni permite entender del todo por qué se ha pasado por alto el argumento propiamente «ético» de Kant en la Segunda Parte de la Metafísica de las Costumbres en defensa del comportamiento protector de la naturaleza. Es indiscutible que la Doctrina de la virtud niega a los seres naturales no humanos el estatus de sujetos morales de deber (ético) por los mismos motivos por los que tampoco se les reconoce - como se mostró antes - la condición de sujetos de derecho. Entre los hombres y el resto de la naturaleza no puede darse, por tanto, una relación de igualdad y reciprocidad éticas como la que se da entre personas morales. Pero ello no significa que el único valor ético de la relación del hombre con la naturaleza tenga el carácter meramente instrumental de servir al fin de la «educación moral» en el trato práctico con los demás hombres o al del autocultivo y perfeccionamiento interior de uno mismo, tal como se ha sostenido habitualmente ${ }^{47}$. Para comprender bien la posición kantiana hay que partir - como ha subrayado $\mathrm{H}$. Baranzke - del contexto doctrinal de los $\S \S 16-17$ de la Doctrina de la virtud y aclarar desde allí por qué Kant sitúa el trato no cruel ni destructivo del medio ambiente precisamente entre los «deberes perfectos del hombre consigo mismo».
Uno se percatará entonces de que la relación con nuestro entorno natural, como asunto de virtud para el ser humano (además de ser una cuestión de derecho), no apunta directamente a las formas virtuosas de relación social con otros hombres ni a la educación para las mismas, ni siquiera a la mejora de la índole moral de cada individuo; muy al contrario, forma parte de un tipo de obligación ética más indispensable, categórica y prioritaria: la que se refiere a la autoconservación de la propia condición moral de la persona del agente. Esclarecida esta conexión ética con la preservación de la dignidad de cada hombre, podrán examinarse posteriormente los términos en los que el comportamiento con la naturaleza compromete al ser moral de cada persona. Kant ha abordado este delicado asunto negando que el compromiso ético con el medio ambiente suponga, para los seres humanos, contraer deberes con el mundo natural, como si éste fuese un sujeto moral («anfibología ético-práctica»), y añadiendo a continuación que se trata más bien de un compromiso de responsabilidad de cada persona consigo misma que tiene por objeto la conservación de nuestro planeta (una obligación ética con respecto a los seres naturales no personales). Esta idea de la protección de la naturaleza como un «deber indirecto» de cada individuo para consigo mismo no es, en realidad, más que la defensa de una virtud muy actual, a la que podríamos denominar «virtud medioambiental». A ambas cuestiones se dedican las páginas siguientes.

\section{a) La protección del medio ambiente como «virtud estricta»: la conservación de la naturaleza como \\ autoconservación de la condición moral del hombre}

La inclusión kantiana de la relación del hombre con la naturaleza al final del tratamiento de los «deberes éticos perfectos del hombre para consigo mismo» en la 
Doctrina de la virtud, ciertamente como una «sección episódica» de ese capítulo ( $\S 16-18)$, pone de manifiesto dos ideas básicas que definen la posición de partida de Kant al respecto: i) que el comportamiento con el entorno natural, al formar parte de los «deberes del hombre para consigo mismo», está relacionado con la conformación moral de cada individuo y, por tanto, entra dentro de las obligaciones de virtud prioritarias, las que se refieren al respeto de la humanidad en la propia persona ${ }^{48}$, sin el cual no es posible respetarla en la persona de los demás hombres ni, por ende, entablar genuinas relaciones morales con ellos; y ii) que la protección del medio ambiente, al constituir además un «deber perfecto (o estricto)» para con uno mismo, $\mathrm{y}$, por ende, un deber cuyo cumplimiento es irrenunciable por concernir a la «salud» o «autoconservación moral» de cada ser humano $\mathrm{y}$, en este caso, sólo a la conservación de su dimensión propiamente inteligible (no de la sensible) ${ }^{49}$, se halla implicada, no en el perfeccionamiento ético de cada hombre, sino en el mantenimiento de su dignidad racional y, por tanto, en la preservación de la condición moral de la especie humana en su conjunto. De ahí que las obligaciones medio ambientales tengan un carácter «negativo» o de prohibición de aquellas acciones que representan por sí mismas una negación del valor moral de la persona o que cuestionan la «receptividad»(o disposición) natural del hombre para el bien ${ }^{50}$, una receptividad que se le supone como ser dotado de razón. Es claro, en este aspecto, que una conducta agresiva contra el paisaje del que formamos parte hasta incluso la aniquilación del mismo o un tratamiento mezquino y cruel de los animales, completamente inútil, son testimonios inequívocos de una pérdida o falta de fuerza moral en el sujeto que así actúa y, por ende, de degradación ética de su persona.
De ahí que, dada esta conexión estricta con el mantenimiento del ser moral del individuo, Kant afirme en las Lecciones de Ética que «se puede conocer el corazón humano también a partir de su relación con los animales»" ${ }^{51}$.

Establecido esto, se entiende ahora el carácter secundario y meramente derivado de los argumentos habituales de los intérpretes sobre el valor exclusivamente instrumental de la relación con el medio ambiente para la educación moral de uno mismo («autocultivo») o de cara al trato con los otros hombres. Todo indica que la hidra de la confusión se ha alimentado de la mezcolanza, en el $\S 17$ de la Doctrina de la virtud, de las razones «pragmáticas» en apoyo de la «disposición moral» del hombre con el argumento genuinamente ético de la acreditación de la misma en cada individuo que se relaciona con la naturaleza sin maltratarla. Pues aunque el debilitamiento del sentimiento estético que se seguiría de una actitud destructiva del mundo inorgánico, así como el «embrutecimiento» y hasta la desaparición de los sentimientos compasivos en la praxis social con los demás seres humanos, que resultaría de un comportamiento violento y cruel con los animales, constituyen formas de barbarie que en nada ayudarían a un hombre a mantener su dignidad, tampoco el desarrollo de las dos formas de receptividad natural correspondientes: la estética y la simpatética, garantizaría nuestra conciencia moral; nos haría ciertamente más «civilizados», pero no nos conduciría a la moralidad misma. De ahí que el argumento ético contra la destrucción de la naturaleza y contra la crueldad con los animales no pueda ser el del deterioro de los sentimientos de belleza y de compasión, sino el de la pérdida de la propia dignidad moral del maltratador ecológico.

Pero ¿por qué el trato con la naturaleza es asunto de virtud para cada hombre hasta el punto incluso de constituir una piedra de toque de su propia índole moral? La res- 
puesta nos remite de nuevo a la orientación mundana del proyecto práctico kantiano de constituirse como sujetos libres en el reino de los fenómenos, y puede formularse así: el mundo natural, carente de por sí de valor alguno, al entrar en el horizonte de acción de un ser libre como el hombre, adquiere el valor relativo, pero indispensable de ser la condición necesaria de realización de la humanidad en la persona humana, de manera que, si se pone en peligro la conservación de nuestro planeta y de todos los seres vivos, se amenazan seriamente las posibilidades de que los hombres se conviertan en sujetos plenamente libres. La protección de la naturaleza es, por tanto, asunto de conservación de la moralidad misma y, en este sentido, forma parte de ésta. Por tanto, la relación utilitaria, instrumental del hombre con su entorno natural y con los seres orgánicos está sujeta siempre a la exigencia de ser compatible con la subjetividad moral de la persona, de suerte que cualquier acción violenta contra la naturaleza, si no obedece a fines morales («uso legítimo»), es por sí misma inmoral, es decir, no puede pensarse más que como incompatible con el privilegio y la tarea de la humanidad en nosotros («uso ilegítimo») y, en este aspecto, nos despoja de nuestra propia dignidad suprasensible. Así, por ejemplo, matar a los animales o hacer experimentos con ellos para fines científicos forma parte - como vimos- del derecho del hombre a su supervivencia y conservación física, pero matarlos cruelmente causándoles un dolor innecesario o experimentar con ellos de manera sádica, sin ningún provecho o aplicación práctica para la vida humana, constituyen actos de mezquindad y de pérdida de «sustancia» ética del individuo que así obra ${ }^{52}$.

\section{b) La «responsabilidad»ética con la naturaleza: "anfibología práctica» y virtud medioambiental}

Una vez examinado el carácter y sentido virtuoso de la protección del medio am- biente, cabe preguntarse ahora por la indole especifica de la obligación ética que comporta. La certidumbre kantiana de que se trata - como hemos visto- de un deber estricto del hombre para consigo mismo deja claro, por un lado, que no estamos ante una obligación contraída por el ser humano con la naturaleza, como si ésta fuese a su vez un sujeto libre y dotado de voluntad; mas justamente por ello no se alcanza a ver, por otro lado, el modo como la relación práctica con seres no personales se constituye en una obligación ética del hombre para con la humanidad en su propia persona. El primer punto ha sido subrayado por Kant al denunciar la suposición de deberes humanos para con otros seres distintos del hombre como una "anfibología de los conceptos morales de reflexión»; a la segunda cuestión, en cambio, se intenta dar una respuesta mediante la observación de que la protección del medio ambiente es, en realidad, una forma «indirecta» de obligación ética de la persona humana para consigo misma. Ambos asuntos están estrechamente relacionados y conjuntamente tratados en el $\S 16$ de la Doctrina de la virtud.

Por lo que atañe al primer punto, la convicción doctrinal de que sólo las personas reales pueden ser sujeto moral de obligación y que, por tanto, únicamente el hombre en la relación consigo mismo o con los demás hombres puede contraer deberes y derechos, lleva a Kant a rechazar la suposición de obligaciones (éticas) para con seres naturales (o no humanos en general) como un «malentendido» al que denomina "anfibología de los conceptos [morales] de reflexión» ${ }^{53}$. Se trata del malentendido consistente en tomar lo que es un «deber del hombre para consigo mismo» por un «presunto deber para con otros seres» ${ }^{54}$. En realidad, el equívoco de quienes creen que hay obligaciones éticas para con seres no-humanos de la natu- 
raleza, según Kant, está en que vinculan un concepto puro de la razón práctica (el de «sujeto moral» a la base de la noción de «deber») con un concepto empírico exclusivo del mundo sensible (el de «ser natural» no humano), de manera análoga a como el quid pro quo de la anfibología trascendental o «especulativa» estaba en no discernir lo que es un objeto (y concepto) del entendimiento puro de lo que es un objeto de la sensibilidad (fenómeno) ${ }^{55}$. De este modo se incurre en una personificación de la naturaleza, esto es, en una atribución de «personalidad numénica» al mundo de la materia, similar a la que ya denunciara Kant en la Doctrina del Derecho Privado a propósito del supuesto derecho inmediato (del trabajador) a la tierra (trabajada) ${ }^{56}$.

La solución del malentendido anfibológico pasa, sin embargo, por reconocer que su origen se halla en la «confusión» o falta de distinción entre dos maneras de presentarse los «deberes del hombre para consigo mismo» en función de su ámbito u objeto de aplicación: el propio sujeto personal (deberes directos) o los seres no personales (deberes indirectos) ${ }^{57}$. Este segundo argumento del $\S 16$ de la Doctrina de la virtud nos permite comprender que el equívoco procede, en realidad, de una visión «antropocéntrica», que limita el territorio de alcance de los deberes éticos exclusivamente a los sujetos personales, y que por ello no es capaz de concebir que los seres naturales distintos del hombre sean objeto de obligación más que convirtiéndolos a su vez en sujetos morales. La distinción kantiana entre «deberes para con» (alguien) [Pflichten gegen] y «deberes con respecto a» (algo) [Pflichten in Ansehung] presupone, sin embargo, una diferenciación clara entre sujeto y objeto de obligación, entre el portador de valores morales y el ámbito objetivo afectado por ellos, gracias a la cual se ofrece una sali- da del malentendido ético con sólo reconocer que el trato con la naturaleza es también objeto de virtud para el hombre, no ciertamente de manera directa (pues el entorno natural no es a su vez «sujeto» moral, ni obligante ni obligado), pero sí indirectamente, porque guarda relación con la subjetividad numénica de cada persona humana, a saber, constituye esa diferencia cualitativa (lo "otro» de sí) a través de la cual se pone a prueba la propia identidad moral (el «sí mismo» libre) y que, por ende, se integra como tal dentro del proyecto de la humanidad en nuestra propia persona. De este modo se introduce también la diversidad en la vida ética del hombre, ya que el ámbito de lo virtuoso acaba alcanzando no sólo a las relaciones de reciprocidad entre sujetos personales, sino también a las relaciones asimétricas entre los seres humanos como sujetos morales y las «cosas» del mundo como objetos que implican una obligación para el hombre.

Esta convicción kantiana de que el trato no destructivo de la naturaleza constituye una forma indirecta de deber con la humanidad en la propia persona de cada hombre, supone la inclusión de la protección del medio ambiente dentro del compromiso moral de cada individuo consigo mismo como un objeto de responsabilidad ética particular, de la que depende la posibilidad de salvaguardar tanto su dignidad personal como la de preservar con ella las mínimas condiciones para el cumplimiento del destino moral de todos y cada uno de los hombres. Pero al mismo tiempo nos permite hablar de virtud medioambiental y definirla como la adquisición por parte de cada persona de una capacidad de mantenerse como ser moral por medio de la constancia en una conducta protectora, o al menos no lesiva de nuestro entorno natural al hacer uso de él. Se trata, por supuesto, de una virtud «negativa», que nos emplaza individualmente a no renunciar a 
nuestra perfección «suprasensible» evitando de continuo el maltrato del planeta y de los seres no humanos que lo habitan en cualquier forma de relación práctica que mantengamos con ellos. Constituye además una virtud perfectamente ajustada a nuestro desiderátum actual de «sostenibilidad» del planeta, ya que simplemente plantea la necesidad de que cada individuo, desde sus peculiares condiciones de relación con el medio natural, restrinja las exigencias del desarrollo y bienestar socioeconómicos, así como las del tratamiento científico y técnico del mundo que nos rodea, al imperativo de salvaguardar su propia integridad moral, haciendo un uso racional, «legítimo» de la naturaleza misma.

Por último, es preciso referirse a las variadas modulaciones de conducta en las que Kant concreta el contenido de la virtud medio ambiental y el alcance de la responsabilidad ética correspondiente. Aquí, haciéndose eco de la experiencia diversa de la naturaleza, el filósofo crítico especifica el comportamiento virtuoso en cada caso en función de las cualidades sensibles que diferencian a los distintos seres no personales de la Tierra, que son elevadas de este modo a criterios empíricos reflexivamente reguladores de la extensión del compromiso de responsabilidad en el trato con esos seres. Así, y aunque comienza haciendo suya la escala natural triádica de Charles Bonnet: naturaleza inorgánica (minerales), naturaleza orgánica carente de sensación (vegetales) y naturaleza orgánica «dotada de sensación, arbitrio» y capacidad representativa (animales) ${ }^{58}$; acaba calibrando, en el $\S 17$, el alcance concreto de la virtud medio ambiental en función de si estamos ante la «naturaleza inanimada» (mundo mineral y vegetal) o ante la «naturaleza viviente» no racional (animales). Conforme a esta distinción empírica, la responsabilidad ética con el mundo inorgánico y vegetal se restringe sólo a la obligación de abstenerse de cualquier espíritu destructivo del mismo que ponga en peligro su utilizabilidad en el futuro, incluida la posibilidad de su disfrute estético. En cambio, cuando se trata de la relación con los animales, que por su capacidad de sentir y su capacidad de acción o movimiento (arbitrio) se acreditan en su conducta externa como seres «análogos» a los humanos ${ }^{59}$, la órbita práctica del compromiso ético ha de ampliarse para acoger esta diferencia específica y, en este aspecto, la prohibición moral de destruir la naturaleza ha de extenderse hasta la obligación de no causar en balde sufrimiento a los animales mediante violencia innecesaria o simple crueldad, así como en el deber incluso de gratitud por los «servicios prestados a lo largo del tiempo», reconociéndolos cual «méritos» (y no sólo trabajos útiles forzados) que requieren recompensa ${ }^{60}$ y en cierto modo agradecimiento (en analogía con los actos humanos de beneficencia), manteniendo a los animales domésticos bajo el propio dominio y sustento, cuando ya no son útiles o están enfermos, "como si fueran miembros de la casa» ${ }^{61}$.

\section{Breves conclusiones}

Del recorrido precedente por la filosofía práctica kantiana para extraer de ella las aportaciones conceptuales más valiosas de cara a la Ética medioambiental contemporánea, conviene retener dos ideas básicas:

1. Kant ha concebido la relación del hombre con la naturaleza como una parte fundamental de su proyecto moral de realización mundana de la humanidad en nuestra persona. En este aspecto, ha defendido el derecho del hombre al uso de las cosas naturales como una exigencia de autonomía 
práctica del individuo en la vida social que se acredita a través de la independencia económica $\mathrm{y}$, por ende, de la propia conservación física de su persona. No cabe duda de que desde esta perspectiva del «dominio» jurídico del planeta el mundo natural sólo es objeto de una relación instrumental con el ser humano, la de un medio útil a su libre disposición.

2. Kant ha considerado, sin embargo, que este dominio utilitario de la naturaleza es no sólo compatible con la conservación de la misma, sino que es moralmente exigible que así sea. En este sentido ha fijado claramente dos límites racionales (morales) al uso de las cosas para impedir la absoluta instrumentalización de las mismas y con ella la posible aniquilación de nuestro hábitat natural. Por un lado, ha restringido el reparto y disposición jurídica de los bienes de la Tierra a las condicio- nes universales y recíprocas de una justicia participativa común de todos los hombres, actuales y futuros, que sólo podrán satisfacerse mediante una legislación «global» sobre el planeta que incluya, obviamente, medidas legales de protección del medio ambiente. Por otro lado, junto a esta limitación jurídica, ha puesto freno también a la mera instrumentalización del entorno natural haciendo de la integridad moral de cada persona el límite ético, el deber irrenunciable al que se halla sujeto todo individuo en su relación de uso con las cosas. De esta manera la conservación de la dignidad del hombre, sea en su persona sensible (autonomía jurídica del arbitrio), sea en su personalidad moral, suprasensible (autonomía ética de la voluntad), constituye el fundamento tanto de la utilización como de la conservación (y protección) de la naturaleza misma.

\section{NOTAS}

\footnotetext{
1 Garve, Christian, Versuche über verschiedene Gegenstände aus der Moral, Literatur und dem gesellschaftlichen Leben, I. Teil, Breslau 1792, pp. 115-16. El mencionado pasaje ha sido reproducido a manera de Apéndice por Henrich, D. (Hrsg.), Kant-Gentz-Rehberg. Über Theorie und Praxis, Suhrkamp, Frankfurt am Main 1967, pp. 134-38.

2 Ingensiep, Hans Werner, «Tierseele und tierethische Argumentation in der deutschen philosophischen Literatur des 18. Jahrhunderts», Internationale Zeitschrift für Geschichte und Ethik der Naturwissenschaften, Technik und Medizin 4: 2 (1996), 103-118, aquí p. 113.

3 Baranzke, Heike, «Tierethik, Tiernatur und Moralanthropologie im Kontext von $\$ 17$ Tugendlehre», Kant-Studien 96:3 (2005), pp. 336-363 ha ofrecido el análisis más claro y contundente del significado moral de la relación del hombre con los animales y demás seres de la naturaleza como «objetos de responsabilidad» humana, ha desmontado con ello las objeciones y tópicos habituales sobre la imposibilidad de una consideración ética del medio ambiente desde la filosofía moral de Kant («antropocentrismo» intelectualista y «especiesismo» antropocéntrico, uso instrumental de la naturaleza para la propia educación pragmática
}

-autocultivo, autocivilización...-, etc.), y la ha rehabilitado para una discusión crítica y desprejuiciada de las posibilidades y límites de fundamentación contemporánea de la Ética medio ambiental. De ahí que algunos de los planteamientos fundamentales del artículo de H. Baranzke sean tenidos muy en cuenta en este trabajo, en el cual, en contraste con la literatura al uso sobre el tema, se contempla también el significado «jurídico» de la relación del hombre con la naturaleza.

4 Algunos teóricos medioambientales han cuestionado el paso conceptual dado por Kant en esta tercera formulación, porque, a su entender, supone una restricción ilegítima del amplio espectro de aplicabilidad del principio de universalizabilidad así como del de posibles sujetos (agentes/pacientes) morales propio de la primera formulación general al ámbito estricto de las personas humanas (cf. Hoff, Christina, «Kant's Invidious Humanism», Environmental Ethics, Spring 1983, vol. 5, n. ${ }^{\circ} 1$, pp. 63-70; y en cierto sentido también Cohn, Priscilla, «Kant y el problema de los derechos de los animales», en Guisán, Esperanza (coord.), Esplendor y miseria de la Ética kantiana, Anthropos, Barcelona 1988, pp. 197-203). Es innegable que con la tercera fórmula del IC el carácter «formal» de la primera se carga de cierto contenido o «materia» (al 
respecto v. Cohen, Hermann, Kants Begründung der Ethik nebst ihren Anwendungen auf Recht, Religion und Geschichte, Bruno Cassirer, Berlin 1910², pp. 226-27; Muguerza, Javier, «Habermas en el "reino de los fines" (Variaciones sobre un tema kantiano)», en: Guisán, E. (1988), pp. 104-105; y Cortina, Adela, «Dignidad y no precio: más allá del economicismo», en Guisán, E. (1988), pp. 160-61, quien sigue a Cohen en este punto), pero ello no significa que el principio de universalidad posible de la acción haya resultado restringido; lo que se restringe con la noción de «humanidad», en cuanto fin en sí de la acción, es sólo el espectro de fines subjetivos particulares que son susceptibles de cualificarse moralmente. Por tanto, el tránsito de una formulación a otra no es, pues, más que el paso del criterio general de racionalidad al criterio de moralidad (cf. Villacañas, José Luis, Racionalidad crítica. Introducción a la filosofía de Kant, Madrid: Tecnos 1987, pp. 171 y ss., y también el artículo del mismo autor, «Kant», en Camps, Victoria (ed.), Historia de la ética. 2. La ética moderna, Barcelona: Crítica 1992, esp. pp. 322-23).

5 Crítica de la razón práctica [KprV] (ed. de Roberto R. Aramayo, Madrid: Alianza 2000, pp. 146-47), A 110. Las obras publicadas por Kant se citan según el título de las (o una de las) ediciones castellanas correspondientes o conforme a la nomenclatura abreviada y estandarizada de las mismas (según las iniciales en alemán), que figura la primera vez entre corchetes, añadiendo a continuación el parágrafo (§), si lo hubiere, y la paginación de la primera (A) y/o segunda edición (B) originales, de acuerdo con la Werkausgabe de W. Weischedel en 12 vols. (Frankfurt/M: Suhrkamp, 1968). Las obras póstumas se citan, en cambio, según la Akademieausgabe de Berlin $[A A]$, volumen y página correspondiente.

${ }^{6}$ Cf. KprV A 155, A 117; Fundamentación para una metafisica de las costumbres [GMS] (ed. de Roberto R. Aramayo, Madrid: Alianza, 2002, pp. 115-16), A 66. Para un análisis exhaustivo de la idea kantiana de «personalidad» y su correspondiente proyección política («personalidad civil»), desde el punto de vista de la aplicación analógica de la categoría relacional de «sustancia» al ámbito de la libertad y de la acción humana, véase Hernández Marcos, Maximiliano, «De la persona moral a la persona civil. Una contribución al republicanismo desde una perspectiva kantiana», Diálogo Filosófico, Madrid, 59, 2004, pp. 295-322 (aquí espec. pp. 303 y ss.).

7 GMS, A 82-83.

$8 \mathrm{KprV}, \S 8$, A 58-59.

9 Cf. Villacañas, J. L. (1987), p. 176.

10 Hernández Marcos, M., «De la persona moral...», p. 306. Esta convicción ético-práctica de la identidad personal del sujeto humano como programa moral fue adquiriendo cada vez más fuerza en el pensamiento de Kant hacia mediados de los ochenta y apuntaló definitivamente su crítica y abandono de la comprensión metafísico-espiritualista de la personali- dad desarrollada por la psicología racional de la escuela leibnizo-wolffiana (cf. Ibidem, pp. 298-299; así como Flórez Miguel, Cirilo, «Theorie der Person: Von der Substanz zur Aktion», en: Funke, G. (ed.), Akten des 5. Internationalen Kant-Kongresses. Mainz 4.-8. April 1981, Bonn 1981, Teil I.2, pp. 1152-1159; y Mohr, G., «Der Begriff der Person bei Kant, Fichte und Hegel», en Sturma, D. (ed.), Person. Philosophiegeschichte - Theoretische Philosophie - Praktische Philosophie, Paderborn 2001, pp. 103-141 (espec. pp. 103-115). Con razón ha basado Heike Baranzke en este carácter proyectivo-práctico de la idea (numénica) de «humanidad» su rechazo de la acusación usual de «especiesismo» antropocéntrico lanzada contra la Ética de Kant por algunos teóricos medioambientales contemporáneos (cf. Baranzke, H., «Tierethik...», p. 350).

11 La metafísica de las costumbres (Madrid: Tecnos, 1989, p. 302), Segunda parte: Principios metafisicos de la doctrina de la virtud (TL), § 12, A 98.

${ }^{12} \mathrm{KprV}$ AB 155. Cf. La metafísica de las costumbres (ed. de Adela Cortina y Jesús Conill, Madrid: Tecnos, 1989, p. 30), Primera Parte: Principios metafisicos de la doctrina del derecho (RL), $\mathrm{AB} 22$. Para esta concepción de la «humanidad» o «personalidad moral» como capacidad o potencia efectiva del sujeto moral, en consonancia con la idea de «virtud» en la tradición republicana, v. Hernández Marcos, M., «De la persona moral...», pp. 304-305 y ss.

13 Kant introduce por ello como categoría relacional de la libertad, en analogía con la «comunidad» de sustancias fenoménicas, «la reciprocidad entre una persona y el estado de otras» (KprV, AB 117).

14 GMS, AB 74 y ss.

15 Los términos «persona» y «personalidad» son a veces usados como intercambiables tanto por el propio Kant como aún más por la literatura kantiana, pero de hecho aluden a conceptos bien discernibles en los principales textos críticos sobre el tema. En efecto, «personalidad» (moral) (véase especialmente KprV) designa exclusivamente la cualidad o propiedad específica del hombre que hace referencia a su dimensión racional o intelectual pura; en cambio, «persona», que es un término polisémico en Kant, en su sentido más frecuente alude al hombre como ser natural especial, distinguido del resto de los seres vivos en virtud de su «personalidad» (moral). Cabe decir, por tanto, que lo novedoso del planteamiento kantiano es su concepción de la persona humana en función de una cualidad específica de ella: la personalidad. Para este concepto de la «persona» (moral) como subordinación práctica del ser sensible del hombre a su condición inteligible (personalidad moral), v. KprV, AB 155; RL, AB 22. Kant ha llegado incluso a acuñar lingüísticamente esta idea mediante la conocida expresión «la humanidad en nuestra propia persona» (o en la persona de otro).

16 Cf. GMS, AB 65; y KprV, AB 155-156. En conexión con esta distinción entre «fines en sí» y «fines/medios» instrumentales se halla la diferenciación 
conceptual ulterior de Kant entre «dignidad» y «precio» en el «reino de los fines», es decir, en el orden teleológico-valorativo del mundo introducido por la perspectiva moral de la realización de la idea de «humanidad» en nuestra persona (cf. GMS, AB 77-78).

$17 M d S$ AB 22-23.

$18 \mathrm{Cf}$. $R L, \mathrm{AB}$ 50-51. En este apartado final de la «Introducción a la Doctrina del Derecho» la clasificación kantiana de las 4 relaciones pensables entre posibles sujetos de obligación (obligantes y obligados) contempla únicamente las relaciones de los «hombres con otros hombres» como relaciones morales «reales entre derecho y deber», porque se entablan entre «seres que tienen tanto derechos como deberes». Kant niega ahí, en cambio, que haya una relación moral real con los «seres irracionales», porque «carecen de derechos y de deberes», pero rechaza también una genuina relación ética con Dios (sería para el hombre sólo una relación de deber, sin correspondientes derechos), porque semejante ser trascendente «no es objeto alguno de la experiencia posible» $\mathrm{y}$, por tanto, no existe como efectivo "sujeto obligante externo» a nosotros y a nuestras ficciones mentales.

19 Aunque - como es sabido - Kant, en su Doctrina del Derecho Privado, contempla tres clases de «derechos adquiridos» («derecho real», «derecho personal», «derecho personal de tipo real»), aquí nos centraremos sólo en el primero de ellos, el derecho a las «cosas corporales» o derecho de propiedad, ya que se refiere directamente a la relación jurídico-práctica del hombre con la naturaleza, núcleo temático, por otro lado, de la primera parte de su Doctrina del Derecho.

20 Cf. $R L, \S 4, \mathrm{AB} 59-60$.

21 Cf. Ibidem, § 4, AB 59-60.

22 Vorarbeiten zu Metaphysik der Sitten, AA XXIII, p. 280. En estos Trabajos preparatorios Kant no sólo distingue entre «libertad como independencia» y «libertad como capacidad [Vermögen]» (cf. AA XXIII, p. 276), sino que además señala que «si todas las cosas fuesen res nullius», la libertad del hombre sería «independencia pero no capacidad» (Ibidem, p. 280). Para una visión más exhaustiva de esta fundamentación kantiana del derecho de propiedad, v. Hernández Marcos, M., $L a$ Crítica de la razón pura como proceso civil. Sobre la interpretación jurídica de la filosofia trascendental de I. Kant, Salamanca: Ed. Universidad de Salamanca (microficha), 1994, pp. 144 y ss.; así como Kersting, W., Wohlgeordnete Freiheit. Immanuel Kants Rechts- und Staatsphilosophie, Berlin/New York, W. de Gruyter, 1984, pp. 113-171; y Brandt, R., Eigentumstheorien von Grotius bis Kant, Stuttgart/Bad Cannstatt: Frommann-Holzboog, 1974, p. 168-201 (espec. 180-193).

${ }^{23} R L, \S 17, \mathrm{AB} 93 ; \S 7, \mathrm{AB} 68-69$.

${ }^{24} R L, \S 2, \mathrm{AB} 56$. Es obvio que sólo la segunda de las dos formulaciones de este postulado jurídico contenidas en el texto citado concierne exclusivamente al «derecho de propiedad» sobre las cosas naturales.
25 «El cuarto y último paso dado por la razón eleva al hombre muy por encima de la sociedad con los animales, al comprender éste (si bien de un modo bastante confuso) que él constituye en realidad el fin de la naturaleza y nada de lo que vive sobre la tierra podría representar una competencia en tal sentido. La primera vez que le dijo a la oveja: la piel que te cubre no te ha sido dada por la naturaleza para ti, sino para mí, arrebatándosela y revistiéndose con ella (Génesis, V, 21), el hombre tomó conciencia de un privilegio que concedía a su naturaleza dominio sobre los animales, a los que ya no consideró como compañeros en la creación, sino como medios e instrumentos para la consecución de sus propósitos arbitrarios») (Probable inicio de la historia humana [en ¿Qué es Ilustración? Y otros escritos de ética, política y filosofía de la historia, ed. de Roberto R. Aramayo, Madrid, Alianza, 2004, p. 164], A 10).

${ }^{26} R L, \S 2, \mathrm{AB} 58$.

27 Ibidem, § 2, AB 58. Sobre el concepto kantiano de ley permisiva, particularmente en relación con el derecho, véase Brandt, R., «Das Erlaubnisgesetz, oder: Vernunft und Geschichte in Kants Rechtslehre», en Brandt, R. (ed.), Rechtsphilosophie der Aufklärung. Symposium Wolfenbüttel 1981, Berlin/New York: W. de Gruyter, 1982, pp. 233-285 (espec. pp. 259-262); y Hernández Marcos, M., «Ley permisiva y realidad del derecho en Kant», en Rodríguez Aramayo, R. y Oncina Coves, F. (comp.), Ética y antropología: un dilema kantiano, Granada, Comares, 1999, pp. 143-164.

28 Cf. $R L, \S 6$ y $\S 13$.

29 Ibidem, § 11, AB 82; cf. AB 81 y § 17, AB 93.

30 Cf. $R L, \S 17, \mathrm{AB} 94$; cf. $\S 11$, A 81-82/B 81.

31 Brandt, R., Eigentumstheorien..., p. 190.

32 Para esta interpretación de la noción kantiana de «posesión común originaria» del suelo terrestre en términos de «justicia participativa», gracias a la cual se podrían fundamentar (y transformar) las así llamadas «cuestiones sociales» no como un asunto de beneficencia privada (liberalismo) o estatal (Estado de bienestar social y de intervención económica) sino como un problema de «derecho privado», a saber, el derecho subjetivo originario de todo hombre a participar en la riqueza común del mundo para desarrollarse como persona humana de manera autónoma, véase Köhler, Michael, «Freiheitliches Rechtsprinzip und Teilhabegerechtigkeit in der modernen Gesellschaft», en Landwehr, G. (ed.), Freiheit, Gleichheit, Selbständigkeit. Zur Aktualität der Rechtsphilosophie Kants für die Gerechtigkeit in der modernen Geselleschaft, Göttingen: Vandenhoeck \& Ruprecht, 1999, pp. 103-128.

33 Cf. $R L, \S \S 8-9$ y $\S 15$.

34 Como es sabido, tanto en el ensayo Sobre el tópico [1793] como en los Trabajos preparatorios del mismo (recogidos por Roberto R. Aramayo en I. Kant, Antología, Península, Barcelona, 1991), Kant caracterizó el concepto jurídico de «propiedad privada» en un sentido más amplio que el de la mera propiedad terrateniente e industrial, para incluir en ella cualquier 
«oficio, arte bella o ciencia» - el trabajo funcionarial-, en la medida en que genere productos susceptibles de venta en el mercado (Über den Gemeinspruch, A 245-246) o conlleve ingresos económicos que quepa «considerar como un derecho a la sustancia» o «a un objeto» ( $A A$ XXIII, p. 137), sin tener que alienar la propia fuerza de trabajo. En este sentido amplio, propiedad privada viene a ser equivalente a actividad laboral autónoma.

35 Cf. $R L, \S 46$, A 166-168/B 196-198. Un tratamiento exhaustivo de este aspecto puede encontrarse en mi artículo «De la persona moral a la persona civil...», 2004, espec. pp. 310 y ss., así como en un trabajo anterior (Hernández Marcos, M., «Kant entre tradición y modernidad: hacia una nueva visión republicana de la sociedad civil», en Martins, A. M. (ed.), Sociedade civil —entre miragem e oportunidade, Coimbra, 2003, pp. 75-102).

36 AA XXIII, p. 341. Cf. Ibidem, 309-310.

37 Cf. Hernández Marcos, M., «Kant entre tradición y modernidad...», pp. 134-136. Kant llega por eso a identificar explícitamente «propiedad» con dominium (cf. $R L, \S 17$, A 95/B 96).

38 Cf. TL, § 17, A 108; y Lecciones de Ética, Barcelona, Crítica, 1988, p. 289.

39 Lecciones de Ética, p. 290.

40 Cf. TL, § 17, A 108; Lecciones de Ética, p. 289.

$41 T L, \S 17, \mathrm{~A} 108$.

$42 R L, \S 17$, A 95/B 96.

43 Cf. Ibidem, § 15, AB 90.

${ }_{44} R L, \S 15, \mathrm{AB} 90$.

45 Se sigue aquí conjuntamente la edición de $\mathrm{R}$. Rodríguez Aramayo: Kant, Immanuel, Lecciones de Ética, Barcelona: Crítica, 1988; y la Moralphilosophie Collins (1784-1785), AA XXVII.1, pp. 241-473, texto en el que se basa, cotejado con la edición de Menzer, Paul, Eine Vorlesung Kants über Ethik, Berlin 1924, la versión española. La exposición de la doctrina kantiana sobre el significado ético de la relación con el medio ambiente se basará, sin embargo, en el texto de la Doctrina de la virtud (1798), que presenta su posición genuinamente crítica. Las Lecciones, a pesar de no contener la concepción madura y definitiva de Kant sobre el tema, serán, con todo, invocadas de manera complementaria para aclarar aquellos puntos doctrinales de la obra de 1798 en los que no haya una clara discrepancia.

Conviene observar, por otro lado, que a partir de ahora se emplea siempre la palabra «ética/o» en el sentido estrictamente kantiano de «virtud» y «virtuoso/a», términos con los que se alude a la moralidad interna (intenciones) de los hombres y de las acciones humanas no susceptible de coacción jurídica (externa).

${ }^{46}$ Cf. Baranzke, H., «Tierethik, Tiernatur...», 2005, pp. 336-337.

47 Para esta interpretación predominante véase, de manera representativa, G. Patzig, Ökologische Ethik -innerhalb der Grenzen blosser Vernunft, Göttingen, 1983, p. 14; y «Der wissenschaftliche Tierversuch un- ter ethischen Aspekten», en: W. Hardegg/G. Preiser (Hg.), Tierversuche und medizinische Ethik. Beiträge zu einem Heidelberger Symposion, Hildesheim, 1986, pp. 68-103, aquí pp. 74-76.

48 Acerca de esta prioridad de los «deberes para consigo mismo» sobre los «deberes para con los demás hombres», en contraste con la tradición filosófica, véase las Lecciones de ética, pp. 157 y ss.

49 Cf. $T L, \S 4$, A 66-68. Acerca de la distinción entre deberes «perfectos» e «imperfectos» v. GMS, nota, A 54; y $T L$, A 20 y ss. Sobre la problemática de esta distinción en Kant v. Kersting, W., Recht, Gerechtigkeit und demokratische Tugend, Frankfurt/M: Suhrkamp, 1997, pp. 76 y ss.; y Baranzke, H., «Tierethik...», pp. 340-42.

$50 T L, \S 4$, A 67 y ss. Para este concepto de receptividad o «disposición moral» véase especialmente el apartado introductorio de la Doctrina de la virtud titulado «Prenociones estéticas de la receptividad del ánimo para los conceptos del deber en general» (TL, A 35 y ss.), así como Hernández Marcos, M., «Sentirse obligado. Reflexiones a partir de Kant», en Andaluz Romanillos, A. (ed.), Kant. Razón y experiencia, Salamanca, Universidad Pontificia, 2005, espec. pp. 230 y ss.

51 Lecciones de Ética, p. 288; cf. Moralphilosophie Collins, AA XXVII.1, p. 459.

52 Cf. Lecciones de Ética, p. 289; TL, § 17, A 108. Desde esta perspectiva, estrictamente crítica, del uso moralmente correcto de nuestro entorno (cf. Baranzke, H., «Tierethik...», p. 354) frente al uso irracional o ilegítimo se disuelven muchos de los problemas que Priscilla Cohn («Kant y el problema de los derechos de los animales», 1988) quiere vislumbrar en las afirmaciones, presuntamente incongruentes, de Kant relativas al comportamiento del hombre con los animales.

53 Cf. $T L, \S 16$, A 106.

54 Ibidem, § 16, A 106. Es sabido que Kant incluye dentro de la «anfibología ético-práctica» todo presunto deber de virtud para con otros seres, tanto los «no personales» pero que son objeto de los «sentidos externos» (seres naturales «no humanos»), como los seres "personales pero absolutamente invisibles», irreales y «sobrehumanos» (seres espirituales puros como «Dios» y los «ángeles» (TL, § 16, A 107). Aquí nos limitaremos a tratar de la anfibología práctica que se produce en relación con los «seres naturales» no humanos, sin abordar el caso de los «espíritus» ni, en particular, de «Dios».

55 Cf. Crítica de la razón pura (ed. de Pedro Ribas, Madrid: Alfaguara, 1978), A 270/B 326.

56 Cf. $R L, \S 17$, A AB 93-94. Aunque Kant sólo contempla la «anfibología ético-práctica» como efecto de una personificación de la naturaleza, es evidente que ese mismo equívoco resultaría de una naturalización de la moral, esto es, de una fundamentación de la subjetividad ética y jurídica en «cualidades empíricas» (psíquicas y/o físicas) del mundo fenoménico, tal como se ha propuesto en el marco de la Ética medio 
ambiental contemporánea por parte del «pathocentrismo» o la «Deep ecology».

57 Cf. $T L, \S 16$, A 106-107. La necesidad de distinguir entre «fundamento de obligación», que concierne a la esencia o fuente moral del deber (es siempre la «personalidad numénica» o subjetividad libre), y «objeto de obligación», que se refiere al ámbito que por ser de interés moral le es aplicable el deber (se trate o no de «sujetos personales»), ha sido subrayada por $\mathrm{H}$. Baranzke, «Tierethik...», pp. 337 y 346-47. Esta autora asimila, no obstante, esa diferenciación a la distinción entre Verpflichtungspartner y Verantwortungsobjekt, y la pone a la base del distingo kantiano entre «deberes directos» $\mathrm{y}$ «deberes indirectos», con el consiguiente error de restringir el campo de los «objetos de responsabilidad» al de las «cosas» o seres no personales, con los cuales sólo hay deberes éticos «indirectos». Sin embargo, la distinción kantiana entre «deberes directos» e «indirectos», que se introduce - no lo olvidemos - para resolver el problema del tipo de vir- tud que comporta el trato del hombre con el mundo no humano (y, particularmente, con el resto del mundo natural), se basa exclusivamente en la diferencia en el «objeto de obligación» en función de si se trata de un sujeto personal o solamente de una «cosa».

\section{$58 T L, \S 16$, A 107.}

59 Cf. Lecciones de Ética, p. 287; Moralphilosophie Collins, AA XXVII.1, p. 459

60 Cf. Moralphilosophie Collins, AA XXVII.1, p. 459.

61 TL, § 17, A 108; cf. Lecciones de Ética, pp. 287-89. No parece que tanto la «compasión» como la «gratitud» para con los animales invocadas aquí tengan el carácter de un "deber de amor», tal como sostiene Baranzke, H, «Tierethik...», pp. 355 y ss. Esto no sólo va contra la doctrina ética kantiana sobre los deberes de benevolencia, sino que sobre todo pasa por alto el nivel «analógico» o metafórico en el que se mueve en concreto el discurso ético de Kant sobre la relación con los animales. 